\title{
Computational Personality Assessment - An Overview and Perspective
}

\author{
Clemens Stachl ${ }^{1}$, Ryan L. Boyd ${ }^{2-4}$, Kai T. Horstmann ${ }^{5}$, Poruz Khambatta ${ }^{6}$, \\ Sandra C. Matz ${ }^{7}$ and Gabriella M. Harari ${ }^{1}$
}

${ }^{1}$ Department of Communication, Stanford University, USA

${ }^{2}$ Department of Psychology, Lancaster University, UK

${ }^{3}$ Security Lancaster, Lancaster University, UK

${ }^{4}$ Data Science Institute, Lancaster University, UK

${ }^{5}$ Institute of Psychology, Humboldt-Universität zu Berlin, Berlin, Germany, EU

${ }^{6}$ Anderson School of Management, UCLA, USA

${ }^{7}$ Columbia Business School, Columbia University, USA

\section{Author Note}

Clemens Stachl iD https://orcid.org/0000-0002-4498-3067

Ryan L. Boyd ID https://orcid.org/0000-0002-1876-6050

Kai T. Horstmann ${ }^{\text {https://orcid.org/0000-0003-3224-1880 }}$

Poruz Khambatta ${ }^{\text {https://orcid.org/0000-0003-1235-2153 }}$

Sandra C. Matz ${ }^{1 D}$ https://orcid.org/0000-0002-0969-4403

Gabriella M. Harari ${ }_{\text {https://orcid.org/0000-0001-9258-9075 }}$

We have no known conflict of interest to disclose. Correspondence concerning this publication should be addressed to Clemens Stachl. Email: cstachl@stanford.edu. 
COMPUTATIONAL PERSONALITY

\begin{abstract}
Computational methods for the representation and analysis of data have drastically increased the objectivity, reliability, and the practical implications of research conducted throughout most scientific pursuits. Our rapidly-emerging potential to transform digital data into objective measures of human behavior, thoughts, and feelings has perfectly positioned personality science as a critical discipline that will benefit from today's ongoing digital revolution. Here, we review and discuss some of the most promising approaches to computational personality assessment based on data from experience sampling, natural language, online social media, mobile sensing, and images. We present a concise overview of key findings, discuss the potential and promise of computational personality assessment, and highlight important remaining questions in their development and application. We conclude with an optimistic outlook on how computational assessment could fuel the transition from personality research to personality science.
\end{abstract}

Keywords: Computational Psychology, Personality, Behavior, Machine Learning, Assessment 


\section{Computational Personality Assessment - An Overview and Perspective}

It has been argued that a scientific discipline's quality can be determined from its tools of measurement (Tal, 2020). A telescope enables far richer views of the heavens than the naked eye, and functional magnetic resonance imaging (fMRI) allows us to uncover the inner workings of a living human brain without ever reaching for a scalpel.

In science, measurement is subject to constant improvement, allowing for more precise quantification of phenomena which, in turn, lead to progress in both theoretical and practical realms. One of the most profound changes that has broadly affected many sciences is the ongoing shift towards computational representations, measurements, and assessments. In this paper we review and discuss how the computational element has and will continue to affect assessment in personality science. We define computational personality assessment as a diagnostic process that involves the use of computational technology for data collection, processing, and decision-making in personality assessment.

In personality psychology, the phenomena of interest are individuals and how they differ in characteristic patterns of thinking, feeling, and behaving. To assess personality, psychologists rely on various forms of assessment, including surveys and diagnostic tests, behavioral observation, and interviews. Such personality assessments are used to efficiently describe and evaluate individuals, compare them to others, and make estimations how they might behave, feel, and think in various situations (Back et al., 2009; Ozer \& Benet-Martínez, 2006). For example, 
COMPUTATIONAL PERSONALITY

personality assessments are used in occupational settings to identify suitable candidates for a vacant position (e.g., conscientiousness; Ziegler, Kemper, \& Kruyen, 2014).

For much of its history, personality psychology has relied on reports by the self or others as the main assessment method (Paulhus \& Vazire, 2007). However, subjective reports have been critiqued for their various shortcomings (e.g., response styles, memory limitations; Vaerenbergh \& Thomas, 2013), and a general consensus has emerged that naturalistic observation of behavior should be considered the 'gold standard' of measurement in personality science (e.g., Baumeister, Vohs, \& Funder, 2007; Boyd, Pasca, \& Lanning, 2020; Zeigler-Hill, Shackelford, Nave, Feeney, \& Furr, 2018).

Despite the widespread agreement regarding the value of naturalistic observation, objective, reliable, and valid measurements of personality-relevant information are inherently difficult to obtain using traditional methods (e.g., ratings provided by human observers). Measurement difficulties arise for many reasons (e.g., costs, participant reactivity, privacy concerns). For example, a typical personality assessment goal might be to determine the extent to which a person is extraverted across situations in general (trait assessment) or in a given situation during a short period of time (state assessment), as opposed to simply observing whether a person is talking (behavioral observation). In Fig. 1 we provide a schematic overview of these approaches. Here, we intentionally distinguish between personality states and raw digital indicators (e.g., behavior) for two reasons. First, because it is possible to assess both personality states and personality traits from digital indicators. Second, because computational personality trait assessment could either involve an intermediate step of personality state assessment (e.g., 
COMPUTATIONAL PERSONALITY

recognizing momentary sociable behavior) or could be performed on behavioral indicators directly (e.g., predicting extraversion trait levels from communication frequencies). The biggest challenge for personality assessment, however, is that the phenomena of interest to personality psychologists are considered as latent constructs that are not directly observable and are assumed to be manifested in patterns of thought, feeling, and behavior over time (Funder, 2009). Typically, in order to assess people's personality at the latent trait level, they had to be asked (Paulhus \& Vazire, 2007) or observed in their thinking, feeling and behaving across situations and over time (Furr, 2009; Sherman et al., 2015).

Observing personality relevant information in the wild is notoriously difficult. However, over the past decade, advances in areas such as machine learning, sensor technology, and online computing alongside the rise of digital devices and platforms (e.g., social media platforms, smartphones) have made behavioral observation studies increasingly viable and have enabled the possibility to use objective metrics in addition to questionnaire items (Montag et al., 2016; Yarkoni, 2012). By providing a means of observing personality-relevant information in daily life, computing technologies introduce new opportunities for the quantification of individual differences in thoughts, feelings, and behaviors.

For example, consider that many of our everyday thoughts, feelings, and behaviors are now mediated, reflected, and often recorded by the ubiquitous technologies that we use on a daily basis (e.g., smartphones, social media). The digital footprint people leave behind can be collected, aggregated, and analyzed for business applications and research alike. In addition, these digital traces can be used to describe, understand, and predict individual differences in people's tendencies to think, feel, behave in characteristic ways (Kosinski et al., 2013). While it 
COMPUTATIONAL PERSONALITY

remains somewhat more challenging to collect information about people's thoughts and feelings, the automated collection of objective behavioral information by technological means has become increasingly feasible. Henceforth, we will primarily focus on personality-relevant behavioral information in this paper.

Advances in computational technology play a crucial role in the development of computational personality assessment, because they allow researchers to represent behaviors digitally and objectively (e.g., a user did or did not "like" a social media post), to collect and store data (e.g., through web scraping tools, smartphone sensing applications), and to analyze data efficiently using computational modeling (e.g., machine learning). The use of computational methods helps us overcome our own human limitations and biases in theory development (e.g., memory limitations when providing self-reports, inability to consider the influence of many factors at the same time, innate tendency to converge to simple theories; Jolly \& Chang, 2019). Hence, a stronger reliance on computational methods will help advance personality science and to create novel, more holistic forms of personality assessment (Stachl, Pargent, et al., 2020).

Research at the intersection of personality psychology and computer science has already begun to harness sources of digital data from online repositories and mobile devices to describe, predict, and better understand individual differences in people's thoughts, feelings, and behavior (e.g., Boyd et al., 2020; Harari et al., 2020). Some of this work has even gone a step further to conceptually explore whether such data can be leveraged for the development of automated computational approaches to personality assessment through predictive modeling (Bleidorn \& Hopwood, 2018; Stachl, Pargent, et al., 2020). Considering the opportunities to collect, store, and model personality-relevant information using computational technologies, there has never 
COMPUTATIONAL PERSONALITY

been a better time to work on the improvement of measurement and assessment in personality psychology, or even in psychology in general.

In this paper, we aim to provide an overview of some of the most promising approaches to the in-vivo, computational conceptualization and assessment of personality. We focus on five sources of behavioral data: experience sampling, smartphone sensing, digital footprints, images, and language data. The data from these sources are not completely independent from each other but may nevertheless provide a useful way of reviewing the research in this burgeoning area. In the remainder of this article, we: (1) highlight the unrealized opportunities these sources of data provide for personality assessment through a computational lens, (2) critically discuss the limitations and challenges of computational personality assessment, and (3) outline necessary steps for future research to begin to overcome these challenges. Finally, we conclude with our perspective on how computational personality assessment could fundamentally change our understanding of individual differences in thoughts, feelings, and behaviors. 


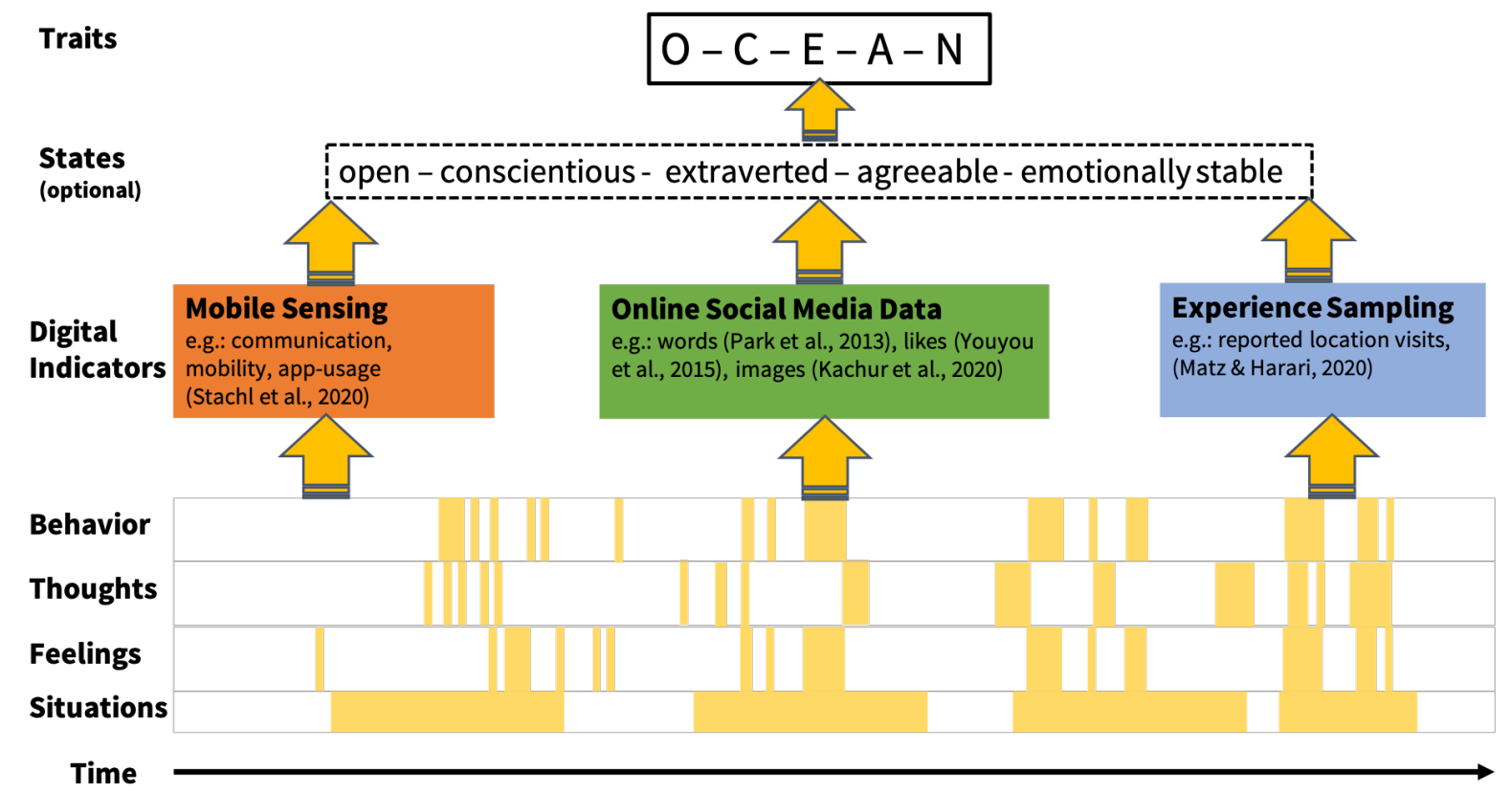

Figure 1. Schematic illustration of computational personality assessment. Patterns of thoughts, feelings and behaviors across situations become accessible as digital indicators of personality through various sources of data. These indicators can either be used to infer personality traits directly or indirectly, via intermediary state prediction. Figure available at https://osf.io/hzrst/, under at a CC-BY4.0 license.

\section{New Data Sources for Computational Personality Assessment}

\section{Experience Sampling Data}

Experience sampling methodology (ESM, also known as Ecological Momentary

Assessment, EMA) describes the repeated assessment of a person's thoughts, feelings, behaviors through self-reports (Horstmann \& Ziegler, 2020). In a sense, it is not a "new method" as it has been around for about a hundred years (Bevans, 2018; Flügel, 1925). Early instances of ESM involved participants actively and repeatedly self-assessing, either by filling out physical, penciland-paper questionnaires manually, by calling an automated phone line, or through the use of early mobile devices like Palm Pilots. Today, however, smartphone- or mobile sensing (see 
COMPUTATIONAL PERSONALITY

section below) is tailored towards the passive detection and recording of objective, personalityrelevant information without any explicit input from users.

However, there has been a recent surge in experience sampling studies in personality psychology and in the way that experience sampling is conducted on a technical level (e.g., using mobile apps; Horstmann \& Ziegler, 2020; Wrzus \& Mehl, 2015). One reason for this resurgence is that most current and prominent theories of personality make predictions about dynamic within-person processes — that is, how a person behaves (or thinks, feels) from moment to moment in interaction with their current environment (e.g., Whole Trait Theory; Fleeson \& Jayawickreme, 2014).

Dynamic personality theories focus on the importance of momentary changes in personality states (Horstmann \& Ziegler, 2020) as a function of environmental and situational influences (Matz \& Harari, 2020), which may be reflected in biological markers (Roberts \& Jackson, 2008). To test and refine dynamic personality theories, it is necessary to assess atomic, transient expressions of personality. Compared to classical one-time self-report questionnaires, ESM greatly reduces the potential impact of memory biases on responses and is therefore thought to be well-suited to assessing momentary personality states. Strictly speaking, ESM is not a purely computational method, because it relies on subjective self-reports. However, ESM is particularly useful to repeatedly collect truly subjective information on qualitative, experiential aspects of personality traits (i.e., momentary feelings and thoughts) that are more difficult to collect with more objective, purely computational approaches (e.g., mobile sensing).

Although its application in personality psychology is relatively new as opposed to its more prevalent use in social psychology, many aspects of ESM as an assessment approach are well-understood: A great deal of knowledge about item design, test development, and the general 
COMPUTATIONAL PERSONALITY

principles of estimating reliability and validity can be transferred or at least adapted from the psychometrics literature (Horstmann \& Ziegler, 2020). For example, a key question that arises when using and interpreting ESM data is related to the issue of validity, or as Hektner, Schmidt, and Csikszentmihalyi, (2007) put it, "whether explanations other than the participants' natural experience can account for their ESM responses." Validity evidence is accumulated over time: the more a measure is used, the better it is understood. ESM has seen substantial use and can therefore fulfill two purposes: First, ESM is comparatively easy to implement and thereby provides a low-investment method for initial tests of a personality theory. For example, personality traits are expected to manifest as personality states, and both traits and states can be assessed with self-reports. A correlation between self-reported traits and states therefore provides initial evidence for the assumption that traits are expressed in daily life - and thus a reason to further investigate the topic.

Second, ESM provides a relatively well-understood source of self-report data that can be used as a complementary reference point when evaluating new approaches to the assessment of personality. For example, Sun \& Vazire, (2019) recently showed that self-reported personality states are related to other-rated personality states based on momentary verbal expressions. Here, the comparatively well-understood self-reports of personality states provided evidence that the other-rated state reports capture "the natural experience" of the participant. Another example is a recent study by Matz \& Harari (2020) showing that the current self-reported location of a participant is related to their self-rated personality states (e.g., feeling more extraverted in bars than at home). In both examples, knowledge about the validity of state-self reports lends credibility to the validity of the new method (i.e., other-reports or the coding of places that are 
COMPUTATIONAL PERSONALITY

psychologically meaningful). Finally, past research proposed to extend classical self-reported ESM items to audio recordings, photographic information, and more objective sensing data (Buschek et al., 2018).

\section{Sensing Data}

Consumer electronics that are equipped with sensing technologies (e.g., wearables, smartphones, smart home appliances) are a pervasive feature of daily life for many people around the world. While as of 2017, an estimated 5\% people in developed nations $(11 \%$ in developing) own smartwatches that they wear on their wrists, an estimated median of $91 \%$ ( $80 \%$ developing) of the developed world's population owns smartphones that they carry around as they go about their day, and an estimated $3 \%$ of people living in developed $(6-10 \%$ in developing) countries own smart home devices that reside in their homes (Deloitte., 2017).

These technologies rely on mobile sensors (e.g., accelerometer, microphone, GPS) and metadata (e.g., system logs) to provide services central to the functioning of the device, such as activity recognition, voice detection, information retrieval, or location tracking (Miller, 2012; Raento et al., 2009). Furthermore, these internet-connected devices are designed to exchange information for a more convenient user experience (e.g., a smartwatch syncing data to a mobile app). However, the data generated from these technologies can also be harnessed to obtain insights into their owners' behavior (e.g., physical activity, social behavior, digital media use; Harari, Müller, Aung, \& Rentfrow, 2017), surrounding environments (e.g., location, ambience; Harari et al., 2018), and personality (Harari et al., 2020; Wiernik et al., 2020). As such, data from sensing technologies present several opportunities for those interested in assessing and understanding the manifestation of personality in daily life. In contrast to self-reports, sensing 
COMPUTATIONAL PERSONALITY

methodologies allow for the collection and quantification of objective data about people's thoughts, feelings, and behaviors.

To date, personality sensing research has focused on the description, explanation, or prediction of personality-relevant information (Harari et al., 2020). In the domains of description and explanation, studies have focused on individual differences in behavior by providing estimates of the rates of engagement in various behaviors (e.g., calling, texting, using different apps; Budimir et al., 2020; Harari et al., 2019; Schoedel et al., 2018; Stachl et al., 2017), identifying the degree to which such behaviors vary between persons, are stable over time, and map onto self-reported personality traits. In the domain of prediction, studies have primarily focused on demonstrating how self-reported personality trait levels can be inferred from sensing data (e.g., Chittaranjan, Blom, \& Gatica-Perez, 2011; Stachl, Au, et al., 2020; Wang et al., 2018), evaluating machine learning models that classify or predict a person's self-reported Big Five trait scores. Cumulatively, personality sensing research provides new insights into people's characteristic behavioral patterns (e.g., stable tendencies, dynamic variability) and new opportunities for automating personality assessment (e.g., self-reported or observed behavioral dimensions; Harari et al., 2020).

Yet, several open questions remain about the replicability of findings reported in past sensing research, whether sensing technologies can (or should) replace other forms of personality assessment (Stachl, Pargent, et al., 2020), and whether sensed behavioral data itself could point to new ways of representing dimensions of individual differences (Boyd et al., 2020).

\section{Digital Footprint Data}


COMPUTATIONAL PERSONALITY

Online social networks (OSNs) have become an integral part of the lives of millions of people around the world (Kosinski et al., 2015). Facebook alone has more than 2.6 billion active daily users, and the Chinese equivalent WeChat is quickly catching up with 1.2 billion users in the first quarter of 2020 and a staggering annual growth rate of 6\%. OSNs - such as Facebook, Twitter, Instagram, Snapchat, or TikTok - allow users to interact with others, broadcast their thoughts and feelings, mobilize for a common cause, or simply peek into the lives of their friends and strangers. Compared to its Western counterparts, WeChat touches on even more aspects of people's lives: It provides the most popular digital form of payment, connects directly to people's bank accounts and offers loans, allows users to book flights and hail taxis, and acts as a real estate platform.

In short, OSNs facilitate almost every aspect of people's lives. And in doing so, they capture enormous amounts of data and information about their users: Their hopes and dreams, preferences and motivations, social connections, daily routines, and physical whereabouts (Matz \& Netzer, 2017).

Similar to the environments we inhabit offline (Gosling et al., 2002), the information captured by OSNs includes both carefully curated identity claims as well as inadvertently generated behavioral residue (Gosling et al., 2011). For example, Facebook users can explicitly and deliberately communicate their interests and preferences using the "Like" button. In contrast, information about a user's current location, or the list of articles and ads they have clicked on while browsing web sites, reflects their preferences more implicitly.

Early research into the psychological underpinnings of OSNs has shown that these seemingly innocuous traces can be used by human judges to make accurate inferences about the 
COMPUTATIONAL PERSONALITY

psychological traits of strangers, including their personality (Gosling et al., 2011). With the growing interest among psychologists in Big Data and machine learning, researchers have increasingly started to investigate the feasibility and validity of automated, computer-based predictions of personality from online digital footprints (Azucar et al., 2018). For example, computational modeling has been used to successfully predict self-reported Big Five personality trait levels from Facebook Likes (Kosinski et al., 2013; Youyou et al., 2015), status updates and Tweets (Park et al., 2015; Quercia et al., 2011; Schwartz et al., 2013), and transaction data (Gladstone et al., 2019). Predictions of personality from OSN profiles have not only been shown to be more accurate that the judgements made by colleagues, friends and family members (Youyou et al., 2015), but they are also known to predict external criteria equally well or even better than people's self-reported responses (Boyd et al., 2015; Park et al., 2015).

Although there is often an inherent tension between the desire to present oneself in a selfidealized way and the desire to present the "true" version of oneself (Back et al., 2010; Ziegler \& Buehner, 2009), this research supports the proposition that users' OSN profiles hold accurate and relevant information about their psychological traits - indeed, even an idealized self-presentation tells us about what a person would like to be, as well as their beliefs about which aspects of the self are important during self-presentation (e.g., (Tong et al., 2020)). OSN profiles act as a window into the psychology of billions of people around the world. This unprecedented ability to automatically retrieve information on peoples' personality at scale has paved the way for OSNs and third parties to use insights into people's personality to shape their experience on the platforms themselves (Matz \& Kosinski, 2019). For example, OSNs and marketers can utilize predictions of personality traits from digital footprints to cater the content a user is exposed within a given platform to their specific psychological needs and preferences (Matz et al., 2017). 


\section{Image Data}

Pictures, including those drawn from social media, personal and professional websites, or offline settings, are rich sources of information and much of this information may be personalityrelevant. For instance, images can be used to represent behaviors (e.g., capturing someone surfing or socializing), thoughts (e.g., memes), and/or feelings (e.g., smiling). Moreover, images can provide information on behavior that has already occurred (i.e., behavioral residue; Gosling et al., 2002) and information that people deliberately choose to display to themselves and others (i.e., identity claims; Gosling et al., 2002). For example, the types of objects a person displays in their office (e.g., books and decorations) has been associated with different personality trait levels (Gosling et al., 2005). Moreover, cameras are embedded in many everyday devices (e.g., smartphones, cars) and are being used in private and public places (e.g., security systems in homes, CCTV systems in cities), providing further visual information about individuals and their behavior that may be analyzed (e.g., Philpot, Liebst, Levine, Bernasco, \& Lindegaard, 2019).

Though the human brain is carefully attuned to make sense of the vast stream of visual data our eyes perceive, this has historically proven much harder for computers. It is quite interesting that computers were able to defeat the world's best chess player (Pandolfini, 1997) many years before they were able to complete visual tasks that nearly any toddler would take for granted (e.g., counting the number of animals in a picture; Szeliski, 2010).

Nonetheless, with the advent of modern computing resources and improved algorithms, researchers have made great strides in the field of computer vision. For example, in recent years, scientists have greatly increased our ability to computationally detect objects, track motion, 
COMPUTATIONAL PERSONALITY

recognize actions, and estimate poses (Voulodimos et al., 2018). Thus, it is natural to wonder whether the same technologies that have enabled these breakthroughs may also allow researchers to analyze images for personality content and even facilitate the automatic assessment of personality traits and states.

Some early work in this space has shown promising results. In one study, participants wore a wearable camera, which took pictures of their environment throughout the day. The objects in these images were automatically classified using computer vision algorithms and were shown to predict both self-reported personality traits and situational characteristics (Blake et al., 2020). In related work, by analyzing online images collected from social media, researchers demonstrated that it is possible to detect personality traits from low-level image features, such as color diversity (Segalin, Celli, et al., 2017) or filters used (Ferwerda et al., 2015).

Despite these advances, one of the most central aspects of a person's image, the face, remains relatively underexplored in personality science. Alongside the progress of the big data revolution, facial images and videos are becoming ever more prevalent, making appearances in profile pictures, social media videos, and online meetings. Even beyond the digital realm, faces are both easily accessible and extremely salient stimuli for human beings. In fact, researchers have argued that most of us will spend more time in our lives looking at faces than we will gazing at anything else (Haxby et al., 2000). It is known that faces can reflect a person's emotional expressions and transient states, but could they offer clues to more enduring psychological dispositions?

Initial investigations in this area show some evidence that this may be possible. In particular, researchers have demonstrated that machine learning models can be trained to predict 
COMPUTATIONAL PERSONALITY

psychological dispositions, including personality, from facial images, such as those on social media (Kachur et al., 2020; Y. Wang \& Kosinski, 2017). Nonetheless, it is important to note some limitations present in the current research in this domain.

First, it is unknown whether such predictions rely on natural facial appearance or other low-level image cues, such as ambient lighting in the photograph. For example, extroverts are more likely to take pictures in bright environments (Segalin, Perina, et al., 2017), and it may be these features, rather than those related to faces that a model is using to form its judgments.

Second, no matter how advanced computer vision becomes, as faces themselves may not perfectly reflect an individual's personality (Todorov et al., 2015), it would be unlikely for image-based detection to fully supplant other forms of personality assessment in terms of their reliability and validity.

Third, important issues need to be resolved regarding privacy and ethics, such as determining whether images taken on a public CCTV camera should ever be analyzed using such algorithms and acknowledgement of the highly problematic, pseudoscientific history of physiognomy - both in science and its gruesome real-world consequences (see Gray, 2004). Importantly, while this research could provide insights into how personality traits manifest in profile pictures or facial expressions in the aggregate, it would be both ill-advised and highly unethical to use such research to judge a particular individual based on how they look in an image. Rather, a far more effective strategy for discovering a stranger's personality would be taking the time to get to know this individual (Letzring et al., 2006) and allowing them agency and control over the process of self-disclosure. Fourth, while static images may convey significant information, the richness and temporal qualities found in videos may allow for even more insight into personality. 
COMPUTATIONAL PERSONALITY

Researchers have already begun to use videos to generate automatic personality assessments (Suen et al., 2019). As such technologies further evolve, new insights and new questions into the manifestation of personality are likely to emerge.

\section{Language \& Audio Data}

Language data (e.g., from text or audio) is one of the main types of personality-relevant information available via computing technologies, such as OSNs and smartphone apps. Moreover, following standardized self-report questionnaires, language data being used as a source of diagnostic information has perhaps one of the oldest traditions in the field of personality assessment. Psychologists have privileged verbal behavior - particularly written and spoken words — as something of a direct pipeline to personality itself. Dating back even to before Psychology's formative days, a person's words were treated as a distillate of their underlying drives, emotions, and thought patterns: the swirling miasma of the preconscious, or the very essence of what ultimately makes someone who they are as a person (Allport, 1942).

Early on, language data within personality science often consisted of conspicuous responding to explicit prompts — such as dream reports, self-description tasks, or projective tests - or cultural artifacts, such as books, newspaper articles, and so on (e.g., Stone et al., 1966). For the past several decades, language data has also been captured as part of the broader stream comprised of one's environment and their interactions with the environment, such as intermittent audio recordings in daily life (Mehl et al., 2001), or even one's social atmosphere (Goldberg et al., 2016). In all cases, the proliferation of smaller, more affordable, and more 
COMPUTATIONAL PERSONALITY

accessible computer technology and OSNs has made the collection and automated analysis of language data increasingly available to researchers across disciplines. Today, it is possible to scrape, quantify, and analyze years of an individual's life through their social media posts in a matter of seconds.

Today, the theoretical underpinnings of analysis of language data are relatively simple when compared to those of the early-to-mid 20th century. From a modern psychometric perspective, language data is most often (though not always) treated as a reflection of one's attentional habits, loosely defined (Boyd et al., 2019; Tausczik \& Pennebaker, 2010). Extraverts, for example, tend to pay more attention to their social environments and other people; consistent with this definition, research finds that extraverts tend to use more "social" words — that is, words about people (e.g., 'friend', 'sister', 'colleague'), generally speaking (see, e.g., Chen et al., 2020; Mairesse et al., 2007; Tackman et al., 2020); Tackman et al., 2020). Importantly, there have been recent calls for expansion of theory and assessment of verbal behavior to more meaningfully align with psychological theory, broadly defined (Boyd \& Schwartz, 2021).

Language data has been used extensively for the passive, non-invasive assessment of personality across a variety of study paradigms. More specifically, personality research with verbal behavior commonly takes language data in its raw, "unstructured" form; words are coded as belonging to different domains: emotions (e.g., 'happy', 'sad', 'nervous'), sociality ('friend', 'family', 'togetherness'), metacognitive ('think', 'understand', 'wonder'), and so on (see, e.g., Fast et al., 2016; Pennebaker et al., 2015). Social media has become a common starting point for personality profiling from language data, with most research centering around blogs (e.g., 
COMPUTATIONAL PERSONALITY

Yarkoni, 2010), Facebook (e.g., Schwartz et al., 2013), and Twitter (Sterling et al., 2020) as data sources. However, the increased digitization of historical documents has also facilitated personality analytics of historical figures (e.g., Boyd \& Pennebaker, 2015; Dean \& Boyd, 2020).

While much of the contemporary language-based research on personality is driven by the goal of maximizing out-of-sample predictive performance — particularly inferences of the Big Five (e.g., Hall \& Caton, 2017; Mehta et al., in press) — others have used language data as the material by which personality itself is conceptualized. For example, Kramer \& Chung, (2011); Pennebaker \& King, (1999) each used language-based psychological measures to conceptualize individuals through their trait-like "thinking styles" and self-expression styles, respectively — a more recent, but conceptually similar, example includes Kulkarni et al.'s (2018) interesting derivation of an exclusively verbal-behavior Big Five.

\section{Discussion}

Having provided an overview of the most promising data types for computational personality assessment, we next turn to a discussion of the key opportunities, challenges, and directions for this area of research. In doing so, our aim is to outline how these sources of data might catalyze new directions of personality research and assessment, while critically discussing the current limitations of these methods and how they might be addressed moving forward (e.g., where they fall short of validated psychometric assessment methods). 


\section{Opportunities}

Computational approaches to personality assessment provide new ways of quantifying individual differences in thoughts, feelings, and behavior and predicting those differences in an automated fashion. Perhaps the most promising aspects of computational personality assessment lie in its increased reliance on more objective sources of data (in comparison with self-reported personality inventories) and its ability to detect complex patterns in large-scale datasets for representation and modeling.

For example, in self-report personality questionnaires, people are asked about their typical behaviors (e.g., their tendency to socialize or be honest in relationships), which can trigger socially desirable response biases. However, digital footprints and mobile sensing data allow for the automated, objective quantification of a person's behaviors (e.g., their tendency to communicate with others or use dating apps while in a relationship). Behavioral observations from digital data sources can reflect personality-relevant information, but do not necessarily represent a person's standing on personality dimensions (e.g., sociability, honesty) on their own. However, when these and other indicators are considered in tandem using computational modeling, they can reveal behavioral patterns that are informative of a person's standing on latent personality dimensions (e.g., outgoing phone calls at night and daily use of communication apps as indicators of Extraversion; Stachl, Au, et al., 2020). It is also known that some aspects of human personality are better assessable by the self, some are better assessable by others - some aspects are neither assessable by the self nor others (Vazire \& Mehl, 2008). For example, people appear to be poor estimators of how they spend their time online (e.g., Junco, 2013), and most people do not have a complete picture of other peoples' online activities. Hence, to assess these 
COMPUTATIONAL PERSONALITY

blind-spots of personality, objective, computational personality assessments could play a decisive role.

Objective behavioral data for computational personality assessment could help to overcome the well-known problems of questionnaire-based assessments (e.g., memory, social desirability, response-styles, faking) and reduce participant burden by enabling passive and automated personality assessment. Additionally, objective behavioral data can be combined with self-reported assessments to provide complementary information on personality traits and states. Consider, for example, a person who spends little time communicating with others (based on sensed data) but reports being a talkative person — this discrepancy may itself reveal key personality information that would not otherwise be available through either source of data by itself.

Computational approaches to personality assessment will enable the quantification of personality expressions in a more fine-grained and holistic way that better accounts for the dynamic components of personality. Specifically, will it allow us to simultaneously model behavioral, situational, cognitive, and emotional processes in a dynamic fashion over time, as described in contemporary personality theories (e.g., Whole Trait Theory, Fleeson \& Jayawickreme, 2014; TESSARA, Wrzus \& Roberts, 2017). This, in turn, will finally enable researchers in personality science to better describe, understand, and predict personality.

In more applied settings, computational personality assessments could also be used for personalizing messages in intervention. For example, personality trait information can be used to tailor messages in political and marketing campaigns to alter peoples' behaviors and decisions 
COMPUTATIONAL PERSONALITY

(Hirsh et al., 2012; Matz et al., 2017; Pezzuti et al., 2021) and to personalize products to individual needs and desires (Tkalcic \& Chen, 2015; Völkel et al., 2019).

\section{Limitations \& Challenges}

Despite these promising opportunities, there are several challenges that currently limit the ability to use these new technologies for personality assessment. One frequent argument against using digital footprints, mobile sensing, and other digital sources of data for assessment purposes is that these new techniques, for the most part, still lack basic evaluations of their psychometric properties (e.g., reliability, validity). For computational personality assessments to be a viable complementary approach to more traditional self-report assessments in applied settings, these new assessments should demonstrate adequate reliability (e.g., over time) and validity (e.g., by predicting relevant life outcomes). One possible benchmark (though certainly not the only one) would be to evaluate the extent to which the new assessment's properties compare to the lowest thresholds for reliable and valid self-reported personality assessments (e.g., single-item measure of Self Esteem; Ten-Item Personality Inventory; Gosling et al., 2003; Robins et al., 2001).

Computational personality assessments from digital behavioral data are currently impaired by the lack of understanding in how reliable obtained personality inferences might be. Several phenomena that are particularly relevant to these new approaches must be considered. For example, concept drifts (cf. longitudinal measurement invariance in psychometrics) refer to a change in the informativeness of digital behavioral indicators that are used as predictors with regard to a criterion (Lu et al., 2019). This effect can lead to the deterioration of a computational 
COMPUTATIONAL PERSONALITY

model for personality assessment over time. In addition, measurement inaccuracies that are induced by the methods themselves can lead to differences in observations (e.g., smartphone sensors across device manufacturers may have different sampling rates). Finally, cultural factors may introduce unique dependencies that may or may not exist in certain cultures or reflect different traits (e.g., "liking" Poutine on Facebook in Canada may be differentially indicative of a person's openness levels than liking it in India).

Another big challenge in computational personality assessment is to test the validity of newly developed models (Tay et al., 2020). In particular, questions arise with regard to whether traditional conceptualizations of validity can be applied "as is" to computational personality assessments (Bleidorn \& Hopwood, 2018; Stachl, Pargent, et al., 2020). For example, traditional conceptualizations used with self-report data, such as the retainment of maximally linear convergent items in a factor structure, may not apply to computational methods because those criterion may not necessarily lead to higher predictive performances, which are the standard by which the new computational methods are evaluated on (Tay et al., 2020). Moreover, digital behavioral data may be indicators of multiple personality dimensions simultaneously, which is inherently different from how self-report measures are developed (e.g., items tend to be used to derive a personality score for a single dimension).

For example, the item "I am a talkative person" is used solely as an indicator of Extraversion in personality trait inventories (unidimensional), but the average number of calls a person makes at night could be an indicator for levels of sociability and self-consciousness (e.g., Stachl, Au, et al., 2020). Such unsolved considerations complicate the validation and development of these new approaches and will need to be overcome to transform computational 
COMPUTATIONAL PERSONALITY

personality assessment research from pure prediction to standardized psychometric tools. One potential way to evaluate the validity of computational personality assessments is to map out the nomological network with regard to relevant life outcomes (e.g., health, occupation satisfaction, and performance; Bleidorn \& Hopwood, 2018). For example, the findings from a study using Facebook Likes to predict Big Five traits showed that the computational assessments were associated with life outcomes (e.g., substance use), suggesting some evidence of external predictive validity (Youyou et al., 2015). However, more specific work is needed with regard to how computational assessments should correlate with life outcomes and at which magnitudes.

Central to the challenge of establishing validity is a more foundational issue regarding the appropriate "ground truth" criteria for evaluating computational personality assessments.

This ground truth problem is present any time a personality prediction model is being developed using new sources of data that include objective quantifications of personality (and self-reports). The ground truth problem can be boiled down to a conceptual question: What is the most representative and unbiased conceptualization of systematic patterns in human feelings, thoughts, and behavior (i.e., personality)? Virtually all of the latest computational approaches to personality assessment rely on self-reported personality trait scores as the ground truth criteria for evaluating the performance of the newly derived assessment models (e.g., Anderson et al., 2020; Azucar et al., 2018; Gladstone et al., 2019; Stachl, Au, et al., 2020). This circumstance is challenging, because it means that computational assessments are also somewhat limited by the methodological biases and issues that are idiosyncratic to questionnaire-based measures - the outcome these models aim to predict (Boyd \& Pennebaker, 2017). Moreover, the direct reliance on self-reports during the development and evaluation of computational models makes it hard to 
COMPUTATIONAL PERSONALITY

argue for advantages of computational approaches in comparison to questionnaire-based methods. For these kinds of models, it is necessary to have "labeled" data for models to be trained on, but by no means does that mean that self-reports are the ultimate criterion to compare against or that models should be optimized to predict. On the contrary, we argue that it should be apparent that aggregated self-reports on peoples' behavioral tendencies should naturally be inferior to direct behavioral assessments of those.

Also, it is questionable how useful the concept of ground truth really is in computational personality assessment in general. It might be rather useful to think of self- and other reported personality information to be complementary to purely behavioral measures as obtained with sensing approaches (Vazire \& Mehl, 2008). While this is no easy problem to solve, one way forward could be to explore whether the full breadth of digital footprints can be statistically combined to allow for the identification of a comprehensive taxonomy of individual differences in thoughts, feelings, and behaviors that is able to directly predict relevant life outcomes and future personality states with reasonable accuracy (Funder, 2012).

It will take time for evidence to accumulate that establishes how valid and reliable new computational personality assessments are. The evaluation of ESM-based assessments could provide a useful point of comparison and model for bridging older and newer methods (e.g., by establishing reliability and validity using nested alphas and factor analyses; Nezlek, 2017). It is likely that hybrid and complementary approaches (e.g., combined assessment via ESM, questionnaire, and mobile sensing) will help to establish the psychometric properties of more complex, computational approaches to personality assessment by highlighting how the various assessments align with another. Initially computational assessments may be used as a supplement 
COMPUTATIONAL PERSONALITY

to self-reports and only later (if at all) start to widely replace the more traditional assessments in real-world applications.

Putting issues of validity aside, the question of how to best conceptualize thoughts and feelings in an objective manner remains unsolved. Related to most extant research, our description of computational personality assessment in this manuscript has primarily focused on digital representation of behavior. However, in order to realize a comprehensive assessment of personality, it is necessary yet much more challenging to objectively observe and quantify what people think and feel. Some recent studies hint at the possibility of measuring cognitive (Brouillette et al., 2013; Gordon et al., 2019; Jach et al., 2020; Wilmer et al., 2017) and affective (Israel \& Schönbrodt, 2020) personality-related processes and states using computational modeling. These approaches are good starting points for further research and highlight the potential of digital physiological metrics (e.g., muscular and brain activity) for the assessment of personality traits and states. Computational modeling will likely play a decisive role in advancing research in this area. One example is the increased use of complex, context-aware transformer models to process human language data (Brown et al., 2020; Devlin et al., 2019). These models are able to provide digital representations of human language (e.g., text) while accounting for at least one level of context (see Boyd \& Schwartz, 2021). Considering their success in natural language processing, it is not far-fetched to imagine the use of these techniques to create representations of other sequential, personality-relevant types of data (e.g., physiological, behavioral, and cognitive signals). Put another way — in the near future, we anticipate an increasing ability to not only measure behaviors, but to ensure that those measurements are modeled in a psychologically accurate way that accounts for context (e.g., 
COMPUTATIONAL PERSONALITY

fidgeting while talking to a romantic interest versus fidgeting while talking to an extremely annoying coworker).

\section{Ethical Considerations}

Computational personality assessments that rely on data related to people's thoughts, feelings and behaviors come with inherent ethical challenges. One of the most obvious ethical implications is how such assessments impact or intrude upon people's privacy. Researchers working in this domain have repeatedly raised concerns that computational personality assessments inevitably threaten individual privacy (Kosinski et al., 2013; Matz et al., 2020), and have offered suggestions for practical and technical solutions as well as legislative action (Harari, 2020; Stachl, Au, et al., 2020). Another ethically difficult aspect of computational personality assessments is the continuous accountability of people for their past actions that is potentially created by the invasiveness and comprehensiveness of the data collection process involved. For example, if personality inferences based on these new approaches are used to decide if a person will get a job, be recommended for promotion, is likely to graduate from college, or is a suitable partner to recommend on a dating app, this is a problematic outcome. It could result in a situation in which people must fear the consequences of every single click or utterance, constraining people's freedom to express themselves free from judgment in an open society. Such concerns could lead to intentional and persistent changes in peoples' behavior (e.g., behave as if you were extraverted) to maximize positive outcomes. This development in turn could cause inferences themselves to no longer be accurate (Gergen, 1973). Further, the issue of accountability is aggravated if combined with a lack of algorithmic fairness (e.g., 
COMPUTATIONAL PERSONALITY

personality assessments are inaccurate for subgroups of the population) and undetected model drifts (Kusner \& Loftus, 2020; Lu et al., 2019). Further, it is possible that different conceptualizations of individual privacy and related ethical positions will influence assessments under cultural and political norms (Andersen, 2020). However, no matter the case, these ethical issues are important topics that warrant due consideration from researchers, policy makers, and the general public.

\section{Outlook \& Conclusion}

Ultimately, we envision two complementary ways of how computational personality assessments could become a worthy alternative and complement to traditional personality assessments. First, computational personality assessment will achieve widespread adoption if it provides additional information or advantages to more traditional forms of personality assessment (e.g., more convenient, cheaper, more accurate, measures different aspects of personality). Second, computational personality assessment will be successful if enough institutions (e.g., academic, corporate, governmental) will engage in it and foster its development. The possibility that corporate and government organizations might engage in computational personality assessment is especially relevant if the conceptual scope of what is considered as personality assessment is broadened. For example, it is possible that computational models of distinct patterns in thoughts, feelings, and behaviors that are predictive of life outcomes could be developed that reflect different conceptualizations of individual differences (e.g., leadership), compared to what personality psychologists are traditionally most concerned with (e.g., latent trait dimensions that provide universal descriptions of individual differences). 
Good science is characterized by the continuous improvement of the methods that it uses to investigate and conceptualize the phenomena of interest. While it is true that sophisticated, mathematical latent variable models have been developed to more precisely measure presumably underlying latent traits in responses form personality questionnaires (e.g., Masters, 1982), it is also a fact that the most promising model in personality psychology (Five Factor Model) is predominantly based on self-reports. On the path from personality research towards personality science, remaining issues with regard to the objectivity, reliability, validity, and ethical considerations of computational personality assessments must be addressed, not only with more studies examining associations between self-reported personality traits levels and self-reported behaviors, but with objective, in-vivo measurements of the factors that could represent individual differences by themselves (Boyd et al., 2020; Mõttus et al., 2020). In a sense, psychology is rapidly expanding the traditional multi-trait-multi-method matrix (Campbell \& Fiske, 1959) by a vast number of new methods and data types. As Roy Amara has famously noted, very often the immediate impact of new technologies is overestimated while the long-term impact of new technologies is underestimated (Ratcliffe, 2016). While computational personality assessment is in its infancy, it could drastically change how personality science is conducted. 
COMPUTATIONAL PERSONALITY

\section{References}

Allport, G. W. (1942). The use of personal documents in psychological science. Social Science Research Council Bulletin.

Andersen, R. (2020, September). China's Artificial Intelligence Surveillance State Goes Global The Atlantic. The Atlantic. https://www.theatlantic.com/magazine/archive/2020/09/china-aisurveillance/614197/

Anderson, I., Gil, S., Gibson, C., Wolf, S., Shapiro, W., Semerci, O., \& Greenberg, D. M. (2020). "Just the Way You Are”: Linking Music Listening on Spotify and Personality. Social Psychological and Personality Science, 194855062092322.

https://doi.org/10.1177/1948550620923228

Azucar, D., Marengo, D., \& Settanni, M. (2018). Predicting the Big 5 personality traits from digital footprints on social media: A meta-analysis. Personality and Individual Differences, 124, 150-159. https://doi.org/10.1016/j.paid.2017.12.018

Back, M. D., Schmukle, S. C., \& Egloff, B. (2009). Predicting actual behavior from the explicit and implicit self-concept of personality. Journal of Personality and Social Psychology, 97(3), 533-548. https://doi.org/10.1037/a0016229

Back, M. D., Stopfer, J. M., Vazire, S., Gaddis, S., Schmukle, S. C., Egloff, B., \& Gosling, S. D. (2010). Facebook profiles reflect actual personality, not self-idealization. Psychological Science, 21(3), 372-374. https://doi.org/10.1177/0956797609360756

Baumeister, R. F., Vohs, K. D., \& Funder, D. C. (2007). Psychology as the Science of SelfReports and Finger Movements: Whatever Happened to Actual Behavior? Perspectives on Psychological Science, 2(4), 396-403. https://doi.org/10.1111/j.1745-6916.2007.00051.x

Bevans, G. E. (2018). How Workingmen Spend Their Spare Time. FRANKLIN CLASSICS 
COMPUTATIONAL PERSONALITY

TRADE Press. https://books.google.at/books?id=UHtbvgEACAAJ

Blake, A. B., Lee, D. I., De La Rosa, R., \& Sherman, R. A. (2020). Wearable cameras, machine vision, and big data analytics: Insights into people and the places they go. In Big data in psychological research. (pp. 125-143). American Psychological Association. https://doi.org/10.1037/0000193-007

Bleidorn, W., \& Hopwood, C. J. (2018). Using Machine Learning to Advance Personality Assessment and Theory. Personality and Social Psychology Review, 108886831877299. https://doi.org/10.1177/1088868318772990

Boyd, R. L., Pasca, P., \& Conroy-Beam, D. (2019). You're Only Jung Once: Building Generalized Motivational Systems Theories Using Contemporary Research on Language. Psychological Inquiry, 30(2), 93-98. https://doi.org/10.1080/1047840X.2019.1633122

Boyd, R. L., Pasca, P., \& Lanning, K. (2020). The Personality Panorama: Conceptualizing Personality Through Big Behavioural Data. European Journal of Personality. https://doi.org/10.1002/per.2254

Boyd, R. L., \& Pennebaker, J. W. (2015). Did Shakespeare Write Double Falsehood? Identifying Individuals by Creating Psychological Signatures With Text Analysis. Psychological Science, 26(5), 570-582. https://doi.org/10.1177/0956797614566658

Boyd, R. L., \& Pennebaker, J. W. (2017). Language-based personality: a new approach to personality in a digital world. In Current Opinion in Behavioral Sciences (Vol. 18, pp. 6368). Elsevier Ltd. https://doi.org/10.1016/j.cobeha.2017.07.017

Boyd, R. L., \& Schwartz, H. A. (2021). Natural language analysis and the psychology of verbal behavior: The past, present, and future states of the field. Journal of Language and Social Psychology, 40(1), 0261927X2096702. https://doi.org/10.1177/0261927X20967028 
COMPUTATIONAL PERSONALITY

Boyd, R. L., Wilson, S. R., Pennebaker, J. W., Kosinski, M., Stillwell, D. J., \& Mihalcea, R. (2015). Values in words: Using language to evaluate and understand personal values. Proceedings of the 9th International Conference on Web and Social Media, ICWSM 2015, $31-40$.

Brouillette, R. M., Foil, H., Fontenot, S., Correro, A., Allen, R., Martin, C. K., Bruce-Keller, A. J., \& Keller, J. N. (2013). Feasibility, Reliability, and Validity of a Smartphone Based Application for the Assessment of Cognitive Function in the Elderly. PLoS ONE, 8(6), e65925. https://doi.org/10.1371/journal.pone.0065925

Brown, T. B., Mann, B., Ryder, N., Subbiah, M., Kaplan, J., Dhariwal, P., Neelakantan, A., Shyam, P., Sastry, G., Askell, A., Agarwal, S., Herbert-Voss, A., Krueger, G., Henighan, T., Child, R., Ramesh, A., Ziegler, D. M., Wu, J., Winter, C., ... Amodei, D. (2020). Language Models are Few-Shot Learners. http://arxiv.org/abs/2005.14165

Budimir, S., Beierle, F., Zimmermann, J., Allemand, M., Neff, P., Pryss, R., Stieger, S., Probst, T., \& Schlee, W. (2020). Frequency and Duration of Daily Smartphone Usage in Relation to Personality Traits. Digital Psychology, 1(1), 20-28. https://doi.org/10.24989/dp.v1i1.1821

Buschek, D., Völkel, S., Stachl, C., Mecke, L., Prange, S., \& Pfeuffer, K. (2018). Experience Sampling as Information Transmission: Perspective and Implications. Ubicomp '18 Workshop: \{Mobile Human Contributions: Opportunities and Challenges\}.

Campbell, D. T., \& Fiske, D. W. (1959). Convergent and discriminant validation by the multitrait-multimethod matrix. Psychological Bulletin, 56(2), 81-105. https://doi.org/10.1037/h0046016

Chen, J., Qiu, L., \& Ho, M. H. R. (2020). A meta-analysis of linguistic markers of extraversion: Positive emotion and social process words. Journal of Research in Personality, 89, 104035. 
COMPUTATIONAL PERSONALITY

https://doi.org/10.1016/j.jrp.2020.104035

Chittaranjan, G., Blom, J., \& Gatica-Perez, D. (2011). Mining large-scale smartphone data for personality studies. Personal Ubiquitous Comput., 17(3), 433-450.

https://doi.org/10.1007/s00779-011-0490-1

Dean, H. J., \& Boyd, R. L. (2020). Deep into that darkness peering: A computational analysis of the role of depression in Edgar Allan Poe's life and death. Journal of Affective Disorders, 266, 482-491. https://doi.org/10.1016/j.jad.2020.01.098

Deloitte. (2017). Global mobile consumer trends, 2nd edition Mobile continues its global reach into all aspects of consumers ' lives.

https://www2.deloitte.com/content/dam/Deloitte/us/Documents/technology-mediatelecommunications/us-global-mobile-consumer-survey-second-edition.pdf

Devlin, J., Chang, M.-W., Lee, K., \& Toutanova, K. (2019). BERT: Pre-training of Deep Bidirectional Transformers for Language Understanding. Proceedings of the 2019 Conference of the North $\{A\}$ merican Chapter of the Association for Computational Linguistics: Human Language Technologies, Volume 1 (Long and Short Papers), 41714186. https://doi.org/10.18653/v1/N19-1423

Fast, E., Chen, B., \& Bernstein, M. S. (2016). Empath: Understanding topic signals in large-scale text. Conference on Human Factors in Computing Systems - Proceedings, 4647-4657. https://doi.org/10.1145/2858036.2858535

Ferwerda, B., Schedl, M., \& Tkalcic, M. (2015). Predicting Personality Traits with Instagram Pictures. Proceedings of the 3rd Workshop on Emotions and Personality in Personalized Systems 2015 - EMPIRE '15, 7-10. https://doi.org/10.1145/2809643.2809644

Fleeson, W., \& Jayawickreme, E. (2014). Whole Trait Theory. Journal of Research in 
COMPUTATIONAL PERSONALITY

Personality. https://doi.org/10.1016/j.jrp.2014.10.009

Flügel, J. C. (1925). A quantitative study of feeling and emotion in everday life. British Journal of Psychology. General Section, 15(4), 318-355. https://doi.org/10.1111/j.20448295.1925.tb00187.x

Funder, D. C. (2009). Persons, behaviors and situations: An agenda for personality psychology in the postwar era. Journal of Research in Personality, 43(2), 120-126. https://doi.org/10.1016/j.jrp.2008.12.041

Funder, D. C. (2012). Accurate Personality Judgment. Current Directions in Psychological Science, 21(3), 177-182. https://doi.org/10.1177/0963721412445309

Furr, R. M. (2009). Personality psychology as a truly behavioural science. European Journal of Personality, 23(5), 369-401. https://doi.org/10.1002/per.724

Gergen, K. J. (1973). Social psychology as history. Journal of Personality and Social Psychology, 26(2), 309-320. https://doi.org/10.1037/h0034436

Gladstone, J. J., Matz, S. C., \& Lemaire, A. (2019). Can Psychological Traits Be Inferred From Spending? Evidence From Transaction Data. Psychological Science, 095679761984943. https://doi.org/10.1177/0956797619849435

Goldberg, A., Srivastava, S. B., Manian, V. G., Monroe, W., \& Potts, C. (2016). Fitting In or Standing Out? The Tradeoffs of Structural and Cultural Embeddedness. American Sociological Review, 81(6), 1190-1222. https://doi.org/10.1177/0003122416671873

Gordon, M. L., Garys, L., Guestrin, C., Bigham, J. P., Trister, A., \& Patel, K. (2019). App usage predicts cognitive ability in older adults. Conference on Human Factors in Computing Systems - Proceedings, 1-12. https://doi.org/10.1145/3290605.3300398

Gosling, S. D., Augustine, A. A., Vazire, S., Holtzman, N., \& Gaddis, S. (2011). Manifestations 
of personality in online social networks: Self-reported facebook-related behaviors and observable profile information. Cyberpsychology, Behavior, and Social Networking, 14(9), 483-488. https://doi.org/10.1089/cyber.2010.0087

Gosling, S. D., Craik, K. H., Martin, N. R., \& Pryor, M. R. (2005). Material Attributes of Personal Living Spaces. Home Cultures, 2(1), 51-87. https://doi.org/10.2752/174063105778053436

Gosling, S. D., Ko, S., Mannarelli, T., \& Morris, M. E. (2002). A room with a cue: Personality judgments based on offices and bedrooms. Journal of Personality and Social Psychology, 82(3), 379-398. https://doi.org/10.1037/0022-3514.82.3.379

Gosling, S. D., Rentfrow, P. J., \& Swann, W. B. (2003). A very brief measure of the Big-Five personality domains. Journal of Research in Personality, 37(6), 504-528. https://doi.org/10.1016/S0092-6566(03)00046-1

Gray, R. T. (2004). About face: German physiognomic thought from Lavater to Auschwitz. Wayne State University Press.

Hall, M., \& Caton, S. (2017). Am I who I say I am? Unobtrusive self-representation and personality recognition on Facebook. PLOS ONE, 12(9), e0184417. https://doi.org/10.1371/journal.pone.0184417

Harari, G. M. (2020). A process-oriented approach to respecting privacy in the context of mobile phone tracking. In Current Opinion in Psychology (Vol. 31, pp. 141-147). Elsevier. https://doi.org/10.1016/j.copsyc.2019.09.007

Harari, G. M., Müller, S. R., Aung, M. S., \& Rentfrow, P. J. (2017). Smartphone sensing methods for studying behavior in everyday life. Current Opinion in Behavioral Sciences, 18, 83-90. https://doi.org/10.1016/j.cobeha.2017.07.018 
COMPUTATIONAL PERSONALITY

Harari, G. M., Müller, S. R., Gosling, S. D., Harari, G. M., Müller, S. R., \& Gosling, S. D. (2018). Naturalistic Assessment of Situations Using Mobile Sensing Methods. In The Oxford Handbook of Psychological Situations.

https://doi.org/10.1093/oxfordhb/9780190263348.013.14

Harari, G. M., Müller, S. R., Stachl, C., Wang, R., Wang, W., Bühner, M., Rentfrow, P. J., Campbell, A. T., \& Gosling, S. D. (2019). Sensing Sociability: Individual Differences in Young Adults' Conversation, Calling, Texting, and App Use Behaviors in Daily Life. Journal of Personality and Social Psychology. https://doi.org/10.1037/pspp0000245

Harari, G. M., Vaid, S. S., Müller, S. R., Stachl, C., Marrero, Z., Schoedel, R., Bühner, M., \& Gosling, S. D. (2020). Personality Sensing for Theory Development and Assessment in the Digital Age. European Journal of Personality, per.2273. https://doi.org/10.1002/per.2273

Haxby, J. V., Hoffman, E. A., \& Gobbini, M. I. (2000). The distributed human neural system for face perception. In Trends in Cognitive Sciences (Vol. 4, Issue 6, pp. 223-233). Elsevier Current Trends. https://doi.org/10.1016/S1364-6613(00)01482-0

Hektner, J. M., Schmidt, J. A., \& Csikszentmihalyi, M. (2007). Experience Sampling Method: Measuring the Quality of Everyday Life. In Experience Sampling Method Measuring the Quality of Everyday Life.

Hirsh, J. B., Kang, S. K., \& Bodenhausen, G. V. (2012). Personalized Persuasion: Tailoring Persuasive Appeals to Recipients’ Personality Traits. Psychological Science, 23(6), 578581. https://doi.org/10.1177/0956797611436349

Horstmann, K. T., \& Ziegler, M. (2020). Assessing Personality States: What to Consider when Constructing Personality State Measures. European Journal of Personality, per.2266. https://doi.org/10.1002/per.2266 
Israel, L. S. F., \& Schönbrodt, F. D. (2020). Predicting affective appraisals from facial expressions and physiology using machine learning. Behavior Research Methods, 1-19. https://doi.org/10.3758/s13428-020-01435-y

Jach, H. K., Feuerriegel, D., \& Smillie, L. D. (2020). Decoding personality trait measures from resting EEG: An exploratory report. Cortex, 130, 158-171. https://doi.org/10.1016/j.cortex.2020.05.013

Jolly, E., \& Chang, L. J. (2019). The Flatland Fallacy: Moving Beyond Low-Dimensional Thinking. Topics in Cognitive Science, 11(2), 433-454. https://doi.org/10.1111/tops.12404

Kachur, A., Osin, E., Davydov, D., Shutilov, K., \& Novokshonov, A. (2020). Assessing the Big Five personality traits using real-life static facial images. Scientific Reports, 10(1). https://doi.org/10.1038/s41598-020-65358-6

Kosinski, M., Matz, S. C., Gosling, S. D., Popov, V., \& Stillwell, D. (2015). Facebook as a research tool for the social sciences: Opportunities, challenges, ethical considerations, and practical guidelines. American Psychologist, 70(6), 543-556. https://doi.org/10.1037/a0039210

Kosinski, M., Stillwell, D., \& Graepel, T. (2013). Private traits and attributes are predictable from digital records of human behavior. Proceedings of the National Academy of Sciences of the United States of America, 110(15), 5802-5805. https://doi.org/10.1073/pnas.1218772110

Kramer, A. D. I., \& Chung, C. K. (2011). Dimensions of self-expression in facebook status updates. Fifth International AAAI Conference on Weblogs and Social Media.

Kulkarni, V., Kern, M. L., Stillwell, D., Kosinski, M., Matz, S., Ungar, L., Skiena, S., \& Schwartz, H. A. (2018). Latent human traits in the language of social media: An open- 
COMPUTATIONAL PERSONALITY

vocabulary approach. PLOS ONE, 13(11), e0201703.

https://doi.org/10.1371/journal.pone.0201703

Kusner, M. J., \& Loftus, J. R. (2020). The long road to fairer algorithms. Nature, 578(7793), 3436. https://doi.org/10.1038/d41586-020-00274-3

Letzring, T. D., Wells, S. M., \& Funder, D. C. (2006). Information quantity and quality affect the realistic accuracy of personality judgment. Journal of Personality and Social Psychology, 91(1), 111-123. https://doi.org/10.1037/0022-3514.91.1.111

Lu, J., Liu, A., Dong, F., Gu, F., Gama, J., \& Zhang, G. (2019). Learning under Concept Drift: A Review. In IEEE Transactions on Knowledge and Data Engineering. https://doi.org/10.1109/TKDE.2018.2876857

Mairesse, F., Walker, M. A., Mehl, M. R., \& Moore, R. K. (2007). Using linguistic cues for the automatic recognition of personality in conversation and text. J. Artif. Int. Res., 30(1), 457500. http://dl.acm.org/citation.cfm?id=1622637.1622649

Masters, G. N. (1982). A rasch model for partial credit scoring. Psychometrika, 47(2), 149-174. https://doi.org/10.1007/BF02296272

Matz, S. C., Appel, R. E., \& Kosinski, M. (2020). Privacy in the age of psychological targeting. Current Opinion in Psychology, 31, 116-121.

https://doi.org/10.1016/J.COPSYC.2019.08.010

Matz, S. C., \& Harari, G. M. (2020). Personality-Place Transactions: Mapping the Relationships Between Big Five Personality Traits, States, and Daily Places. Journal of Personality and Social Psychology. https://doi.org/10.1037/pspp0000297

Matz, S. C., \& Kosinski, M. (2019). Using Consumers’ Digital Footprints for More Persuasive Mass Communication. NIM Marketing Intelligence Review, 11(2), 18-23. 
COMPUTATIONAL PERSONALITY

https://doi.org/10.2478/nimmir-2019-0011

Matz, S. C., Kosinski, M., Nave, G., \& Stillwell, D. J. (2017). Psychological targeting as an effective approach to digital mass persuasion. Proceedings of the National Academy of Sciences of the United States of America, 114(48), 12714-12719.

https://doi.org/10.1073/pnas.1710966114

Matz, S. C., \& Netzer, O. (2017). Using Big Data as a window into consumers' psychology. In Current Opinion in Behavioral Sciences (Vol. 18, pp. 7-12). Elsevier Ltd. https://doi.org/10.1016/j.cobeha.2017.05.009

Mehl, M. R., Pennebaker, J. W., Crow, D. M., Dabbs, J., \& Price, J. H. (2001). The Electronically Activated Recorder (EAR): a device for sampling naturalistic daily activities and conversations. Behavior Research Methods, Instruments, \& Computers : A Journal of the Psychonomic Society, Inc, 33(4), 517-523. https://doi.org/10.3758/BF03195410

Mehta, Y., Fatehi, S., Kazameini, A., Stachl, C., Cambria, E., \& Eetemadi, S. (n.d.). Bottom-Up and Top-Down: Predicting Personality with Psycholinguistic and Language Model Features. https://www.kaggle.com/datasnaek/mbti-type

Miller, G. (2012). The Smartphone Psychology Manifesto. Perspectives on Psychological Science, 7(3), 221-237. https://doi.org/10.1177/1745691612441215

Montag, C., Duke, É., Markowetz, A., \& Markowetz, A. (2016). Toward Psychoinformatics: Computer Science Meets Psychology. Computational and Mathematical Methods in Medicine, 2016, 1-10. https://doi.org/10.1155/2016/2983685

Mõttus, R., Wood, D., Condon, D. M., Back, M., Baumert, A., Costantini, G., Epskamp, S., Greiff, S., Johnson, W., Lukaszewski, A., Murray, A., Revelle, W., Wright, A., Yarkoni, T., Ziegler, M., \& Zimmermann, J. (2020). Descriptive, predictive and explanatory personality 
COMPUTATIONAL PERSONALITY

research: Different goals, different approaches, but a shared need to move beyond the Big Few traits. In European Journal of Personality. PsyArXiv.

https://doi.org/10.31234/OSF.IO/HVK5P

Nave, C. S., Feeney, M. G., \& Furr, R. M. (2018). Behavioral Observation in the Study of Personality and Individual Differences. In The SAGE Handbook of Personality and Individual Differences: Volume I: The Science of Personality and Individual Differences (pp. 317-340). SAGE Publications Ltd. https://doi.org/10.4135/9781526451163.n15

Nezlek, J. B. (2017). A practical guide to understanding reliability in studies of within-person variability. Journal of Research in Personality, 69, 149-155.

https://doi.org/10.1016/j.jrp.2016.06.020

Ozer, D. J., \& Benet-Martínez, V. (2006). Personality and the Prediction of Consequential Outcomes. Annual Review of Psychology, 57(1), 401-421. https://doi.org/10.1146/annurev.psych.57.102904.190127

Pandolfini, B. (1997). Kasparov and Deep Blue: The Historic Chess Match between Man and Machine. Simon \&amp; Schuster Trade.

Park, G., Schwartz, H. A., Eichstaedt, J. C., Kern, M. L., Kosinski, M., Stillwell, D. J., Ungar, L. H., \& Seligman, M. E. P. (2015). Automatic Personality Assessment Through Social Media Language. Journal of Personality and Social Psychology, 108(6), 934-952. https://doi.org/10.1037/pspp0000020

Paulhus, D. L., \& Vazire, S. (2007). The self-report method. In R. W. Robins, R. C. Fraley, \& R. F. Krueger (Eds.), Handbook of research methods in personality psychology (pp. 224-239). Guilford Press.

http://books.google.com/books?hl=en\&lr=\&id=XHwS3PU6uroC\&oi=fnd\&pg=PA224\&dq 
COMPUTATIONAL PERSONALITY

$=$ The + self-report + method\&ots $=$ JBJjUXTRTG\&sig $=$ i_Lja4kJJxGgW5PkdHfdhM63Tw

Pennebaker, J. W., Boyd, R. L., Jordan, K., \& Blackburn, K. (2015). The development and psychometric properties of LIWC2015.

https://repositories.lib.utexas.edu/handle/2152/31333

Pennebaker, J. W., \& King, L. A. (1999). Linguistic styles: language use as an individual difference. Journal of Personality and Social Psychology, 77(6), 1296-1312.

http://www.ncbi.nlm.nih.gov/pubmed/10626371

Pezzuti, T., Leonhardt, J. M., \& Warren, C. (2021). Certainty in Language Increases Consumer Engagement on Social Media. Journal of Interactive Marketing, 53, 32-46.

https://doi.org/10.1016/j.intmar.2020.06.005

Philpot, R., Liebst, L. S., Levine, M., Bernasco, W., \& Lindegaard, M. R. (2019). Would I Be Helped? Cross-National CCTV Footage Shows That Intervention Is the Norm in Public Conflicts. American Psychologist. https://doi.org/10.1037/amp0000469

Quercia, D., Kosinski, M., Stillwell, D., \& Crowcroft, J. (2011). Our Twitter Profiles, Our Selves: Predicting Personality with Twitter. 2011 IEEE Third Int'l Conference on Privacy, Security, Risk and Trust and 2011 IEEE Third Int'l Conference on Social Computing, 180185. https://doi.org/10.1109/PASSAT/SocialCom.2011.26

Raento, M., Oulasvirta, A., \& Eagle, N. (2009). Smartphones: An Emerging Tool for Social Scientists. Sociological Methods \& Research, 37(3), 426-454.

https://doi.org/10.1177/0049124108330005

Ratcliffe, S. (Ed.). (2016). Oxford Essential Quotations (Vol. 1). Oxford University Press. https://doi.org/10.1093/acref/9780191826719.001.0001

Roberts, B. W., \& Jackson, J. J. (2008). Sociogenomic personality psychology. In Journal of 
Personality (Vol. 76, Issue 6, pp. 1523-1544). NIH Public Access. https://doi.org/10.1111/j.1467-6494.2008.00530.x

Robins, R. W., Hendin, H. M., \& Trzesniewski, K. H. (2001). Measuring Global Self-Esteem: Construct Validation of a Single-Item Measure and the Rosenberg Self-Esteem Scale. Personality and Social Psychology Bulletin, 27(2), 151-161. https://doi.org/10.1177/0146167201272002

Schoedel, R., Au, Q., Völkel, S. T., Lehmann, F., Becker, D., Bühner, M., Bischl, B., Hussmann, H., \& Stachl, C. (2018). Digital Footprints of Sensation Seeking. Zeitschrift Für Psychologie, 226(4), 232-245. https://doi.org/10.1027/2151-2604/a000342

Schwartz, H. A., Eichstaedt, J. C., Kern, M. L., Dziurzynski, L., Ramones, S. M., Agrawal, M., Shah, A., Kosinski, M., Stillwell, D., Seligman, M. E. P., \& Ungar, L. H. (2013). Personality, gender, and age in the language of social media: the open-vocabulary approach. PloS One, 8(9), e73791. https://doi.org/10.1371/journal.pone.0073791

Segalin, C., Celli, F., Polonio, L., Kosinski, M., Stillwell, D., Sebe, N., Cristani, M., \& Lepri, B. (2017). What your facebook profile picture reveals about your personality. MM 2017 Proceedings of the 2017 ACM Multimedia Conference, 460-468. https://doi.org/10.1145/3123266.3123331

Segalin, C., Perina, A., Cristani, M., \& Vinciarelli, A. (2017). The Pictures We Like Are Our Image: Continuous Mapping of Favorite Pictures into Self-Assessed and Attributed Personality Traits. IEEE Transactions on Affective Computing, 8(2), 268-285. https://doi.org/10.1109/TAFFC.2016.2516994

Sherman, R. A., Rauthmann, J. F., Brown, N. A., Serfass, D. G., \& Jones, A. B. (2015). The independent effects of personality and situations on real-time expressions of behavior and 
COMPUTATIONAL PERSONALITY

emotion. Journal of Personality and Social Psychology, 109(5), 872-888.

https://doi.org/10.1037/pspp0000036

Stachl, C., Au, Q., Schoedel, R., Gosling, S. D., Harari, G. M., Buschek, D., Völkel, S. T., Schuwerk, T., Oldemeier, M., Ullmann, T., Hussmann, H., Bischl, B., \& Bühner, M. (2020). Predicting personality from patterns of behavior collected with smartphones. Proceedings of the National Academy of Sciences of the United States of America, 117(30), 17680-17687. https://doi.org/10.1073/pnas.1920484117

Stachl, C., Hilbert, S., Au, J. Q., Buschek, D., De Luca, A., Bischl, B., Hussmann, H., \& Bühner, M. (2017). Personality Traits Predict Smartphone Usage. European Journal of Personality, 31(6), 701-722. https://doi.org/10.1002/per.2113

Stachl, C., Pargent, F., Hilbert, S., Harari, G. M., Schoedel, R., Vaid, S., Gosling, S. D., \& Bühner, M. (2020). Personality Research and Assessment in the Era of Machine Learning. European Journal of Personality, per.2257. https://doi.org/10.1002/per.2257

Sterling, J., Jost, J. T., \& Bonneau, R. (2020). Political psycholinguistics: A comprehensive analysis of the language habits of liberal and conservative social media users. Journal of Personality and Social Psychology, 118(4), 805-834. https://doi.org/10.1037/pspp0000275

Stone, P. J., Dunphy, D. C., \& Smith, M. S. (1966). The general inquirer: A computer approach to content analysis. In The general inquirer: A computer approach to content analysis. M.I.T. Press.

Suen, H. Y., Hung, K. E., \& Lin, C. L. (2019). TensorFlow-Based Automatic Personality Recognition Used in Asynchronous Video Interviews. In IEEE Access (Vol. 7, pp. 6101861023). Institute of Electrical and Electronics Engineers Inc.

https://doi.org/10.1109/ACCESS.2019.2902863 
Sun, J., \& Vazire, S. (2019). Do People Know What They're Like in the Moment? Psychological Science, 30(3), 405-414. https://doi.org/10.1177/0956797618818476

Szeliski, R. (2010). Computer Vision: Algorithms and Applications. Springer-Verlag.

Tackman, A. M., Baranski, E. N., Danvers, A. F., Sbarra, D. A., Raison, C. L., Moseley, S. A., Polsinelli, A. J., \& Mehl, M. R. (2020). 'Personality in Its Natural Habitat' Revisited: A Pooled, Multi-sample Examination of the Relationships Between the Big Five Personality Traits and Daily Behaviour and Language Use. European Journal of Personality, per.2283. https://doi.org/10.1002/per.2283

Tal, E. (2020). Measurement in Science. In E. N. Zalta (Ed.), The Stanford Encyclopedia of Philosophy (Fall 2020). Metaphysics Research Lab, Stanford University.

Tausczik, Y. R., \& Pennebaker, J. W. (2010). The Psychological Meaning of Words: LIWC and Computerized Text Analysis Methods. Journal of Language and Social Psychology, 29(1), 24-54. https://doi.org/10.1177/0261927X09351676

Tay, L., Woo, S. E., Hickman, L., \& Saef, R. M. (2020). Psychometric and Validity Issues in Machine Learning Approaches to Personality Assessment: A Focus on Social Media Text Mining. European Journal of Personality, per.2290. https://doi.org/10.1002/per.2290

Tkalcic, M., \& Chen, L. (2015). Personality and Recommender Systems. In Recommender Systems Handbook (pp. 715-739). Springer.

Todorov, A., Olivola, C. Y., Dotsch, R., \& Mende-Siedlecki, P. (2015). Social attributions from faces: Determinants, consequences, accuracy, and functional significance. Annual Review of Psychology, 66, 519-545. https://doi.org/10.1146/annurev-psych-113011-143831

Tong, S. T., Corriero, E. F., Wibowo, K. A., Makki, T. W., \& Slatcher, R. B. (2020). Selfpresentation and impressions of personality through text-based online dating profiles: A 
COMPUTATIONAL PERSONALITY

lens model analysis. New Media \& Society, 22(5), 875-895.

https://doi.org/10.1177/1461444819872678

Vaerenbergh, Y. Van, \& Thomas, T. D. (2013). Response styles in survey research: A literature review of antecedents, consequences, and remedies. International Journal of Public Opinion Research, 25(2), 195-217. https://doi.org/10.1093/ijpor/eds021

Vazire, S., \& Mehl, M. R. (2008). Knowing me, knowing you: the accuracy and unique predictive validity of self-ratings and other-ratings of daily behavior. Journal of Personality and Social Psychology, 95(5), 1202-1216. https://doi.org/10.1037/a0013314

Völkel, S. T., Schödel, R., Buschek, D., Stachl, C., Au, Q., Bischl, B., B"uhner, M., \& Hussmann, H. (2019). Opportunities and Challenges of Utilizing Personality Traits for Personalization in HCI: Towards a shared perspective from HCI and Psychology. In Personalized Human-Computer Interaction. De Gruyter.

Voulodimos, A., Doulamis, N., Doulamis, A., \& Protopapadakis, E. (2018). Deep Learning for Computer Vision: A Brief Review. Computational Intelligence and Neuroscience, 2018, 7068349. https://doi.org/10.1155/2018/7068349

Wang, W., Harari, G. M., Wang, R., Müller, S. R., Mirjafari, S., Masaba, K., \& Campbell, A. T. (2018). Sensing Behavioral Change over Time: Using Within-Person Variability Features from Mobile Sensing to Predict Personality Traits. Proceedings of the ACM on Interactive, Mobile, Wearable and Ubiquitous Technologies, 2(3), 1-21.

https://doi.org/10.1145/3264951

Wang, Y., \& Kosinski, M. (2017). Deep Neural Networks Can Detect Sexual Orientation From Faces. Journal of Personality and Social Psychology.

https://doi.org/10.17605/OSF.IO/HV28A 
Wiernik, B. M., Ones, D. S., Marlin, B. M., Giordano, C., Dilchert, S., Mercado, B. K., Stanek, K. C., Birkland, A., Wang, Y., Ellis, B., Yazar, Y., Kostal, J. W., Kumar, S., Hnat, T., Ertin, E., Sano, A., Ganesan, D. K., Choudhoury, T., \& Al'Absi, M. (2020). Using Mobile Sensors to Study Personality Dynamics. European Journal of Psychological Assessment, 113. https://doi.org/10.1027/1015-5759/a000576

Wilmer, H. H., Sherman, L. E., \& Chein, J. M. (2017). Smartphones and Cognition: A Review of Research Exploring the Links between Mobile Technology Habits and Cognitive Functioning. Frontiers in Psychology, 8, 605. https://doi.org/10.3389/fpsyg.2017.00605

Wrzus, C., \& Mehl, M. R. (2015). Lab and/or Field? Measuring Personality Processes and Their Social Consequences. European Journal of Personality, 29(2), 250-271. https://doi.org/10.1002/per.1986

Wrzus, C., \& Roberts, B. W. (2017). Processes of Personality Development in Adulthood: The TESSERA Framework. Personality and Social Psychology Review, 21(3), 253-277. https://doi.org/10.1177/1088868316652279

Yarkoni, T. (2010). Personality in 100,000 Words: A large-scale analysis of personality and word use among bloggers. Journal of Research in Personality, 44(3), 363-373. https://doi.org/10.1016/j.jrp.2010.04.001

Yarkoni, T. (2012). Psychoinformatics: New Horizons at the Interface of the Psychological and Computing Sciences. Current Directions in Psychological Science, 21(6), 391-397. https://doi.org/10.1177/0963721412457362

Youyou, W., Kosinski, M., \& Stillwell, D. (2015). Computer-based personality judgments are more accurate than those made by humans. Proceedings of the National Academy of Sciences of the United States of America, 112(4), 1036-1040. 
COMPUTATIONAL PERSONALITY

https://doi.org/10.1073/pnas. 1418680112

Ziegler, M., \& Buehner, M. (2009). Modeling Socially Desirable Responding and Its Effects. Educational and Psychological Measurement, 69(4), 548-565.

https://doi.org/10.1177/0013164408324469

Ziegler, M., Kemper, C. J., \& Kruyen, P. (2014). Short Scales - Five Misunderstandings and Ways to Overcome Them. Journal of Individual Differences, 35(4), 185-189.

https://doi.org/10.1027/1614-0001/a000148 